\title{
Mapping Landslide Susceptibility and Analyzing Its Impact on Community Livelihoods in Gakenke District, Northern Rwanda
}

\author{
Mucyo Jean Claude, Nsanzumukiza Vincent Martin*, Maniragaba Abias, \\ Mukasekuru Francoise, Uwemeye Johnson, Kagame Tonny, Uwera Martine
}

Department of Environmental Economics and Natural Resources Management, Faculty of Environmental Studies, University of Lay Adventists of Kigali, Kigali, Rwanda

Email: *nsanzumumartiv@gmail.com

How to cite this paper: Claude, M. J., Martin, N. V., Abias, M., Francoise, M., Johnson, U., Tonny, K., \& Martine, U. (2020). Mapping Landslide Susceptibility and Analyzing Its Impact on Community Livelihoods in Gakenke District, Northern Rwanda. Journal of Geoscience and Environment Protection, 8, 41-55.

https://doi.org/10.4236/gep.2020.85003

Received: March 27, 2020

Accepted: May 5, 2020

Published: May 8, 2020

Copyright $\odot 2020$ by author(s) and Scientific Research Publishing Inc. This work is licensed under the Creative Commons Attribution International License (CC BY 4.0).

http://creativecommons.org/licenses/by/4.0/ (c) (i) Open Access

\begin{abstract}
This study spatially distributed landslide susceptibility and assessed its impact on community livelihoods in Gakenke district of Rwanda. The Global Positioning System (GPS) located recent landslides from which inventory map was built. Six conditioning factors: elevation, slope, land use and land cover, rainfall, soil texture and lithology were analyzed by Geographic Information System (GIS) to map landslide susceptibility. The results showed that Janja, Muzo, Kamubuga, Kivuruga and Muyongwe sector are highly susceptible to landslide. The elevation, slope, poor land management and rainfall are the key drivers to landslide in this area. The findings indicated that the residents are not aware of landslide causal factors due to low level of education and trainings. Also, rain harvest which could minimize the runoff is not yet practiced; this in turn impacts on people's livelihoods by killing/injuring people, damaging their infrastructures and natural resources. Therefore, it is suggested to empower rainwater harvest, deliver education and training to enhance community awareness, and ensure that the local community is involved in planning and execution of landside risk reduction schedule.
\end{abstract}

\section{Keywords}

Community, Gakenke District, GIS, Landslide Susceptibility, Livelihoods

\section{Introduction}

The occurrence of landslide cause considerable losses and damages to vulnerable people. This is mainly increasing due to the fact that the risk reduction policies are top-bottom while community involvement can help to empower their miti- 
gation and adaptation capabilities (Anderson \& Holcombe, 2013). It is reported that landslide causes $17 \%$ of all casualties of natural hazards in the world and it is predicted that in the future, with the increase in urbanization, deforestation, and changes in climate conditions, landslide occurrence will grow (Armaş, 2011; Ayalew et al., 2005; Akgün \& Bulut, 2007). One of the main approaches for developing hazard reduction strategies is creating the landslide susceptibility maps (LSM) (Murillo-García et al., 2017). The landslide susceptibility mapping (LSM) has a significant role in risk mitigation of landslides since it can provide spatial distribution of potential slope failures (Felicísimo et al., 2013).

Future landslides are more likely to occur in the areas which were previously affected with landslides (Murillo-García et al., 2015; Claeys et al., 2017). Landslide susceptibility map identifies areas which are subject to landslides and is measured from low to high. The landslide susceptibility map takes into account where the landslides occur and the causes of landslide such as slope, soil type and the impact of the flow of water in a given area (Abdulwahid \& Pradhan, 2017). Previous reports indicated that since 1960s, there have been disaster records in Rwanda such as flood, landslides, droughts, famine, earthquakes and volcanic eruptions. These hazards affected people's lives (killed, injured and homeless), damaged croplands, livestock loss, and destroyed infrastructures (Piller, 2016; Wagesho \& Claire, 2016; Nsengiyumva et al., 2018). Today flood and landslides are the major concerns among others, and are largely being registered by the north-western zones of Rwanda (Bizimana \& Sönmez 2015). Specifically, high rate of poverty and population density, elevated land, slope and frequent torrential rainfall are the major causes of landslide occurrence in Rwanda (Nsengiyumva et al., 2018).

In Rwanda, the north western is the largely affected zone by landslide. Hence, based on the fact that landslide is gradually causing damages and losses among people, it is good not only to map landslide susceptibility but also, to assess the local community's awareness on its exposure, and the extent to which their susceptibility impact on people's livelihoods would help to envisage appropriate risk reduction measures. In Gakenke district, the topography has direct influences on the intensity and character of landslides, high elevation and slope, deforestation and inappropriate land use are responsible for soil erosion in Gakenke district along with its frequent and torrential rainfall leading to usual occurrence of landslide (Benineza et al., 2019). In this area, only one study (Benineza et al., 2019) has been conducted to assess landslide hazard. The study only used elevation, slope, soil types and rainfall as conditioning factors and omitted assessing community disaster awareness. This expresses lack of scientific studies employing a series of factors and integrating community perception in order to enable both policy makers and community to realize the required hazard management measures. Therefore, this study aimed at mapping landslide susceptibility; and assessing community susceptibility awareness and its impact on livelihoods in Gakenke district of the northern province of Rwanda. 


\section{Methods and Materials}

\subsection{Study Area}

This study was conducted in Gakenke district, one of five districts of Northern Province of Rwanda. The district borders with Rulindo district at its Eastern side, Burera and Musanze districts at its North, Nyabihu district at its West, and at the South, by Kamonyi and Muhanga districts (Benineza et al., 2019). The district is divided into 19 administrative sectors and occupies a surface area of $704.1 \mathrm{~km}^{2}$, and a total population of 338,234. The population density of Gakenke District is $503 \mathrm{hab} / \mathrm{km}^{2}$ (Benineza et al., 2019). Figures 1(a)-(c) illustrates the location of Gakenke district and its bordering districts, its sectors and landslide inventory.

\subsection{Samples and Data Collection}

\section{Landslide Inventory}

The study of van Western et al., (2008) suggested that for landslide susceptibility assessment, it is good to consider past distribution of landslide. This is due to the fact that factors that led to past landslide occurrence in the area of study if reoccurred, may result from the same factors. For the present study, historical record and field surveys identified 14 past landslides from which the landslide inventory map (Figure 1(c)) was prepared. The last events were recorded by using the Global Positioning System (GPS) with assistance of local residents. Furthermore, after building landslide susceptibility map, the local communities were approached in order to assess their awareness on their landslide susceptibility and its impact on their livelihoods. For this case, the dead and/or injured people, damaged infrastructures (roads, hospitals, and schools), affected livestock were

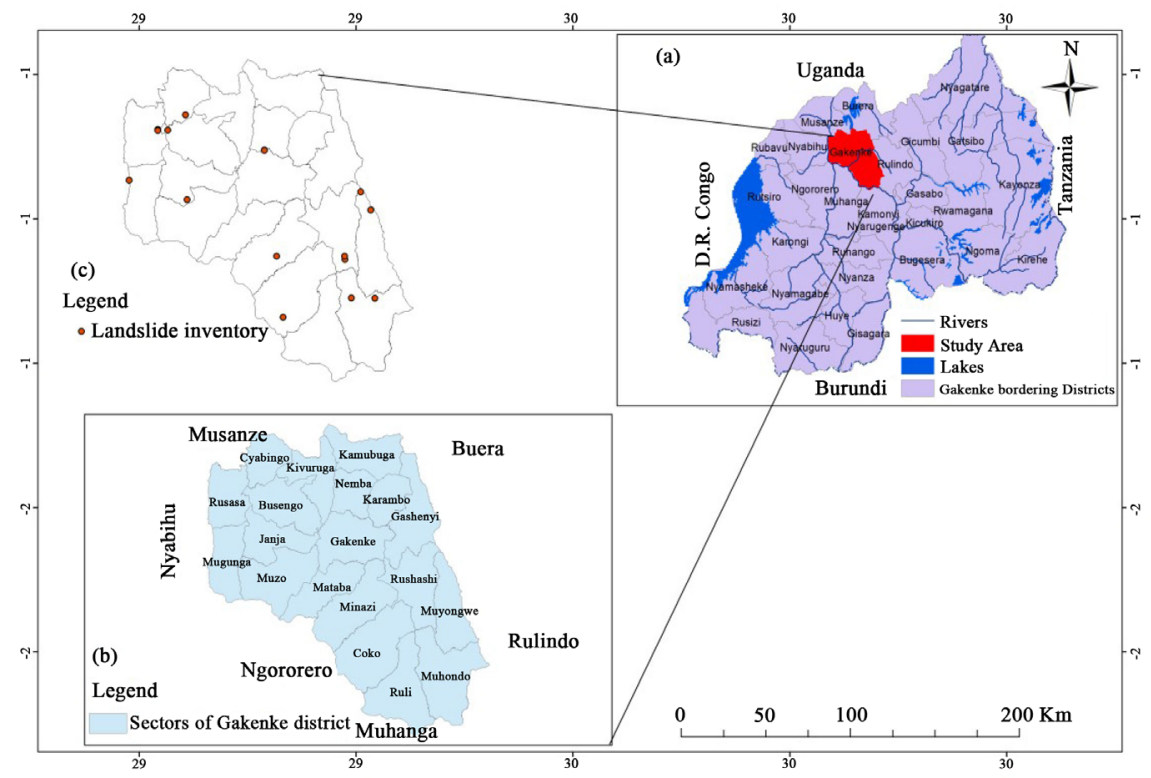

Figure 1. Location of Gakenke district in Rwanda (a), its sectors (b) and landslide inventory $(c)$. 
considered. The key informants were purposively selected such as leaders and other community representatives in order to assess their views on landslide susceptibility. In all sector, sample size was selected randomly by using the Yamane formula (Yamane, 1992), for calculating the sample from the population of Gakenke district, Equation (1):

$$
n=\frac{N}{1+N e^{2}}
$$

where $n$ is the sample size, $N$ is the population size, and $e$ is the levels of precision. To minimize the risk that the sample size might not represent the true population, the margin error was fixed at $10 \%$. Therefore, the sample became:

$$
n=\frac{338324}{1+338324 \times 0.1^{2}}=99.9 \simeq 100
$$

Thus, as indicated in the Equation (2), a sample of one hundred (100) was used. However, this number is too high to be covered; hence, the study were divided into the total 19 sectors in order to obtain the sample size per each sector. Thereafter, the authors calculated the sample per each sector considered by this study. The proportionate sampling method was used (Kim et al., 2014), to determine the number of respondents per sector, Equation (3):

$$
n i=\frac{N i * n}{N}
$$

where $n i$ is the sample size proportion to be determined, $N i$ is the population proportion in the sector, $n$ is the sample size calculated in Equation (2) and $N$ is the total population considered by the study. Therefore, the proportion of popu-

\begin{tabular}{|c|c|c|}
\hline Sector & Population & Sample size \\
\hline Busengo & 20,164 & 6 \\
\hline Coko & 16,340 & 5 \\
\hline Cyabingo & 17,544 & 5 \\
\hline Gakenke & 22,670 & 7 \\
\hline Gashenyi & 20,067 & 6 \\
\hline Janja & 15,804 & 5 \\
\hline Kamubuga & 20,758 & 6 \\
\hline Karambo & 12,159 & 3 \\
\hline Kivuruga & 18,226 & 5 \\
\hline Mataba & 14,346 & 4 \\
\hline Minazi & 13,527 & 4 \\
\hline Mugunga & 19,361 & 6 \\
\hline Muhondo & 20,125 & 6 \\
\hline Muyongwe & 15,550 & 4 \\
\hline Muzo & 21,378 & 6 \\
\hline Nemba & 15,643 & 7 \\
\hline Ruli & 18,516 & 5 \\
\hline Rusasa & 18,250 & 5 \\
\hline Rushashi & 17,806 & 5 \\
\hline Total & 338,234 & 100 \\
\hline
\end{tabular}
lation in each sector is shown in Table 1.

Table 1. Sample size per sector. 
To collect the information from the sample size, a structured questionnaire was used. In order to collect data from residents of the district, from each sector, the respondents were purposively selected based on targeted women, youth representatives, socio-economic agents at sector level, local residents, schools, hospitals and church leaders.

\subsection{Data Analysis}

The collected datasets were processed and analyzed. The Statistical Index (SI) Model was used to estimate the contribution of the used causal factors to landslide occurrence. The Statistical Index (SI) is accepted as bivariate statistical method (Van Westen et al., 1997). The model has a basis requiring calibration from correlation between known incidents. In the model, the weighting value for each conditioning factor class is defined as the natural logarithm of the landslides density in a class divided by landslides density in the entire map (Van Westen et al., 1997). The statistical index is calculated using Equation (4).

$$
W i j=\operatorname{In}\left(\frac{\text { DensClasij }}{\text { DensMap }}\right)=\operatorname{In}\left[\frac{\frac{\text { Npix }(\text { Sij })}{\text { Npix }(\mathrm{Nij})}}{\frac{\sum_{\mathrm{j}} \mathrm{Npix}(\mathrm{Sij})}{\sum_{\mathrm{j}} \mathrm{Npix}(\mathrm{Nij})}}\right]
$$

where $\mathrm{Wij}$ is the weight for class $\mathrm{j}$ within the triggering factor map I, DensClasij is density of landslides in class $j$ within the triggering factor mapI, DensMap is the density of landslides in the entire map, $\mathrm{Npix}(\mathrm{Sij})$ is the number of pixels in class $j$ within the triggering factor map I and $\mathrm{Npix}(\mathrm{Nij})$ is the number of pixels in class $j$ within the triggering factor map i. Based on Equation (4), the landslide susceptibility map was produced.

$$
\begin{aligned}
\text { LSIsi }= & \text { Wsi }(\text { elevation })+\text { Wsi }(\text { slope angel })+\text { Wsi }(\text { rainfall }) \\
& + \text { Wsi }(\text { lithology })+\text { Wsi }(\text { soil texure }) \\
& + \text { Wsi }(\text { Land use and land cover })
\end{aligned}
$$

where LSIsi is landslides susceptibility index with statistical index and Wsi is the weight of each landslides conditioning factor determined by the statistical index model. The map of landside susceptibility was built by using the Geographical Information System (GIS) in its Spatial Analysist Tools which helped to merge the SI values of all used factors and indicate the resulting landslide susceptibility. Furthermore, after building landslide susceptibility in this area, the data collected through the questionnaire were analyzed by using the Statistical Package for Social Sciences (SPSS) Software.

\section{Results and Discussion}

\subsection{Landslide Susceptibility Conditioning Factors}

The six landslide conditioning factors such as elevation, slope, rainfall, land use and land cover, soil texture and lithology were assessed. Elevation and slope an- 
gles used, (Figure 2(a) and Figure 2(b)) were derived from Digital Elevation Model (DEM) of $30 \mathrm{~m}$ resolution. These datasets were acquired from the United States Geological Survey Earth Explorer (USGS, 2018). The five elevation classes were: 1343 - $1595 \mathrm{~m}, 1595-1764 \mathrm{~m}, 1764-1934 \mathrm{~m}, 1934-2150 \mathrm{~m}$ and 2150 $2654 \mathrm{~m}$. The classes of slope in angles were from $0-15^{\circ}, 15^{\circ}-25^{\circ}, 25^{\circ}-35^{\circ}$, and $35^{\circ}-45^{\circ}$ and $>45^{\circ}$. The report on rainfall and disaster in Rwanda were considered, mainly northern part of Rwanda where Gakenke district is located, in this areas more than $70 \%$ of landslide occurrence and losses are rainfall-induced (MIDIMAR, 2014). Monthly precipitation data were interpolated by using 28 years data from 1990 to 2018, rainfall data collected from meteorological stations operating countrywide. The data were provided by the Rwanda Meteorology Agency (RMA, 2018). The mean monthly rainfall (Figure 2(c)) were in the range of $0-50 \mathrm{~mm}, 50-60 \mathrm{~mm}, 60-70 \mathrm{~mm}, 70-80 \mathrm{~mm}$ and $>80 \mathrm{~mm}$.

The type of the land coverage represents the likelihood of the land exposure to erosion and runoff risks including landslide. The land use and land cover (LULC) map of 2019 was produced from multispectral Landsat-8, Operational Land Imager (OLI) images. These images were acquired from the United States Geological Survey Earth Explorer (USGS, 2018). The land cover/use map was classified and five land use and land cover (LULC) classes, (Figure 3(a)) were produced based on the East African Classification of Regional Center for Mapping and Resources Development (Belle et al., 2014). Finally, the lithological and geological features used, (Figure 3(a) and Figure 3(b)) were derived from Rwandan geological, mining and soil databases (Rushemuka et al., 2014). The three lithology classes were schist, basic igneous rock and water bodies. Whereas four soil texture classes were sand clay loam, clay loam, sand clay and clay.

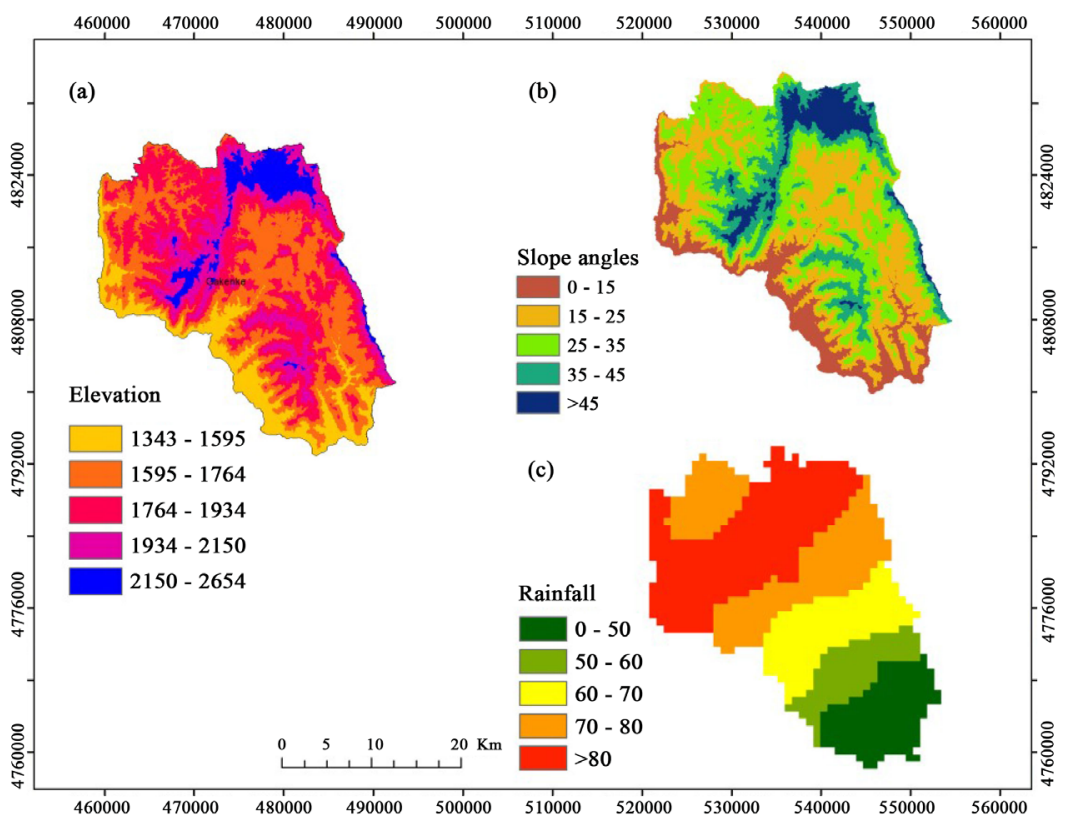

Figure 2. Elevation in meters (a); Slope angles in degrees (b) and Rainfall in millimeters (c) distribution in Gakenke district. 


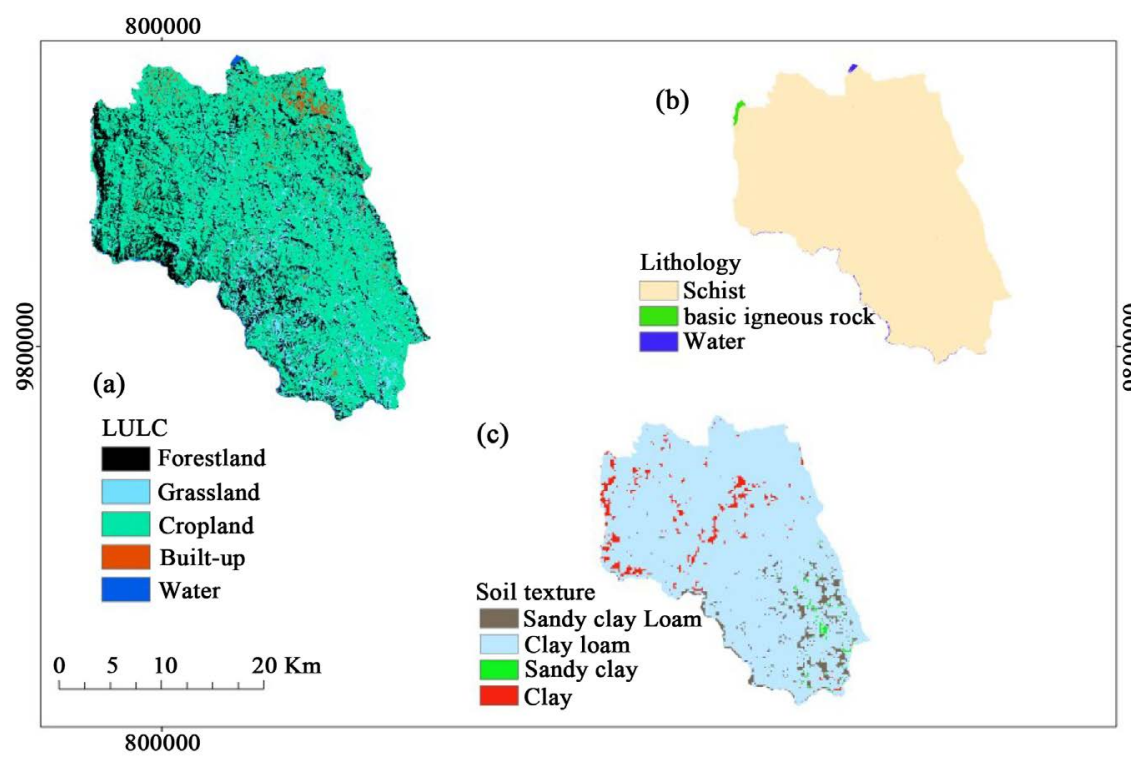

Figure 3. Land use and Land Cover (a), Lithology (b) and Soil texture of Gakenke district.

\subsection{Landslide Susceptibility Mapping}

The eight conditioning factors which likely cause the occurrence of landslide and exposure among people were identified. The results on the spatial relationship between each landslide conditioning factor and landslide occurrence by the SI Model are shown in Table 2. The results indicated that high SI values of elevation are mainly in the classes of $2150-2654 \mathrm{~m}$ (2.32) and the elevation classes of $1934-2150 \mathrm{~m}$ and $1343-1596 \mathrm{~m}$ which recorded an SI value of 1.82 , respectively. With regard to slope angles, it was noted that high SI value are in the slope angles of 25 - 35 degrees and 15 - 25 degrees which recorded 0.39 and 0.31 SI values, respectively.For the rainfall, highest SI value was in the ranges of 50 $60 \mathrm{~mm}(0.82)$ and 0.58 for $>80 \mathrm{~mm}$. Also, the results in Table 2 pointed out the schist as the dominating lithological class with high SI value (0.81). In addition, among other soil textures, the SI model indicated the clay (0.37) and sandy clay loam (0.24) as the major soil texture class which conditions landslide occurrence in this area. For the land use and land cover, the results in Table 2 revealed high SI values of 1.13, 0.86 and 0.62 for the land use classes of cropland, grassland and forest, respectively.

The results in Figure 4 indicated that in Gakenke district, the susceptibility to landslide is experienced differently. Some parts of the district are under high susceptibility while others are in the middle or low susceptibility to landslide. This expresses that the considered causal factors contribute to landslide occurrence at different extent within the district and that the risk reduction should consider each area's susceptibility class.

The results in Figure 4 indicated that Kamubuga sector is largely susceptible to landslide in this district followed by Janja, Muzo, Muyongwe and Kivuruga sectors. Similarly, regardless the types and number of conditioning factors employed, the results of the study conducted by Benineza et al. (2009) in this area 


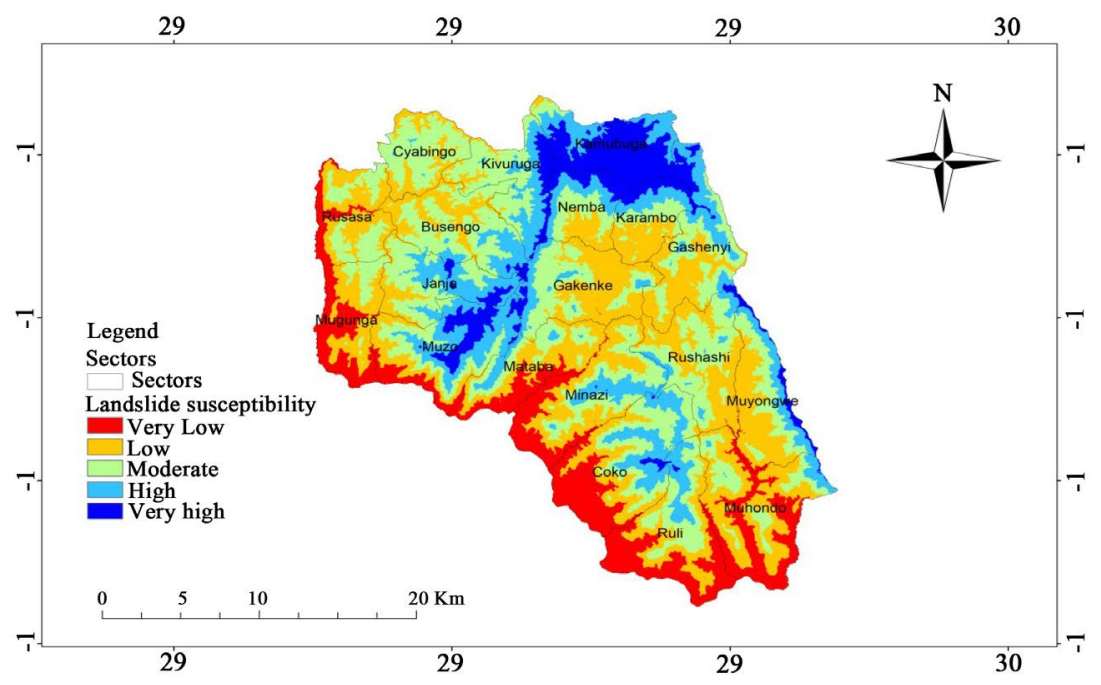

Figure 4. Landslide susceptibility map of Gakenke district.

Table 2. Relationship between landslide occurrence and conditioning factors by SI model.

\begin{tabular}{|c|c|c|c|c|c|}
\hline Factors & Classes & Class domain (\%) & No. landslides & No. landslide pixels & SI \\
\hline \multirow[t]{5}{*}{ Elevation } & $2150-2654$ & 3.7 & 1 & 1036 & 2.32 \\
\hline & $1934-2150$ & 8.8 & 2 & 1372 & 1.82 \\
\hline & $1764-1934$ & 34 & 4 & 3468 & 1.42 \\
\hline & $1595-1764$ & 38.2 & 3 & 3196 & 0.67 \\
\hline & $1343-1596$ & 15.3 & 2 & 1372 & 1.82 \\
\hline \multirow[t]{5}{*}{ Slope angles } & $>45$ & 1.2 & 1 & 3069 & 0.26 \\
\hline & $35-45$ & 9.4 & 2 & 1427 & 0.21 \\
\hline & $25-35$ & 39.4 & 4 & 3791 & 0.39 \\
\hline & $15-25$ & 36 & 3 & 3548 & 0.31 \\
\hline & $0-15$ & 26 & 2 & 2978 & 0.12 \\
\hline \multirow[t]{5}{*}{ Rainfall } & $>80$ & 21.6 & 3 & 3114 & 0.58 \\
\hline & $70-80$ & 22.1 & 3 & 3320 & 0.54 \\
\hline & $60-70$ & 19.7 & 3 & 3219 & 0.54 \\
\hline & $50-60$ & 34.3 & 4 & 4201 & 0.82 \\
\hline & $0-50$ & 2.3 & 2 & 1123 & 0.26 \\
\hline \multirow[t]{3}{*}{ Lithology } & Basic igneous rock & 0.8 & 0 & 193 & 0.11 \\
\hline & Schist & 99.1 & 12 & 4642 & 0.81 \\
\hline & Water & 0.1 & 0 & 179 & 0.04 \\
\hline \multirow[t]{4}{*}{ Soil texture } & Sandy clay loamy & 12.1 & 3 & 2651 & 1.24 \\
\hline & Clay loamy & 31.3 & 3 & 2519 & 0.19 \\
\hline & Sand clay & 8.6 & 2 & 1242 & 0.12 \\
\hline & Clay & 48.4 & 4 & 4984 & 0.37 \\
\hline \multirow[t]{5}{*}{ LULC } & Built-up land & 6.2 & 1 & 1237 & 0.29 \\
\hline & Cropland & 39.4 & 4 & 4328 & 1.13 \\
\hline & Grassland & 26.2 & 3 & 1801 & 0.62 \\
\hline & Forest & 26.1 & 3 & 1971 & 0.86 \\
\hline & Water Bodies & 2.1 & 0 & 1003 & -0.31 \\
\hline
\end{tabular}


confirmed that Kamubuga sector is highly vulnerable to landslide. Thus, appropriate hazard management should prioritize this sector. The findings in Figure 5 confirmed this exposure to landslide of those sectors mainly due to their high elevation, slope, rainfall and poor land management. This expresses that landslide risk reduction initiatives should consider these key factors, primarily conditioning landslide occurrence and exposing the residents to the losses.

\subsection{Impact of Landslide Susceptibility on Community Livelihoods}

Landslide is among the major geological hazards which impact on community's livelihoods. However, it is reported (Shaw, 2012; Bhatta et al., 2016) that full involvement of local people in understanding the causal factors and the extent of their exposure can help to minimize the losses. This is mainly due to the fact that local people's indigenous knowledge enables them to better understand their living area's reality and can be based on while formulating relevant risk reduction.

Among the contacted respondents, the results in Table 3 showed that 36 percent are aged between 18 and 30 years old followed by 29 percent who are aged between 30 and 42 years old. And 58 percent of them are female while 44 percent and 32 percent attended secondary and primary schools, respectively. The local community in this area is at low level aware of exposure to landslide. The results revealed that the channels used to improve people's awareness on landslide occurrence and causal factors are mainly local meetings, radio and television (Table 4).

The delivery of trainings and courses on landslide in this area is still at low pace (Table 4). This can be the reason of the noticed gradual impact on community livelihoods mainly people dead and injured, destructed infrastructures, and damage of natural resources (Table 5). Accordingly, this expresses that the local community is approached but not provided with full information regarding the causes of landslide occurrence and their impact on life and livelihoods.

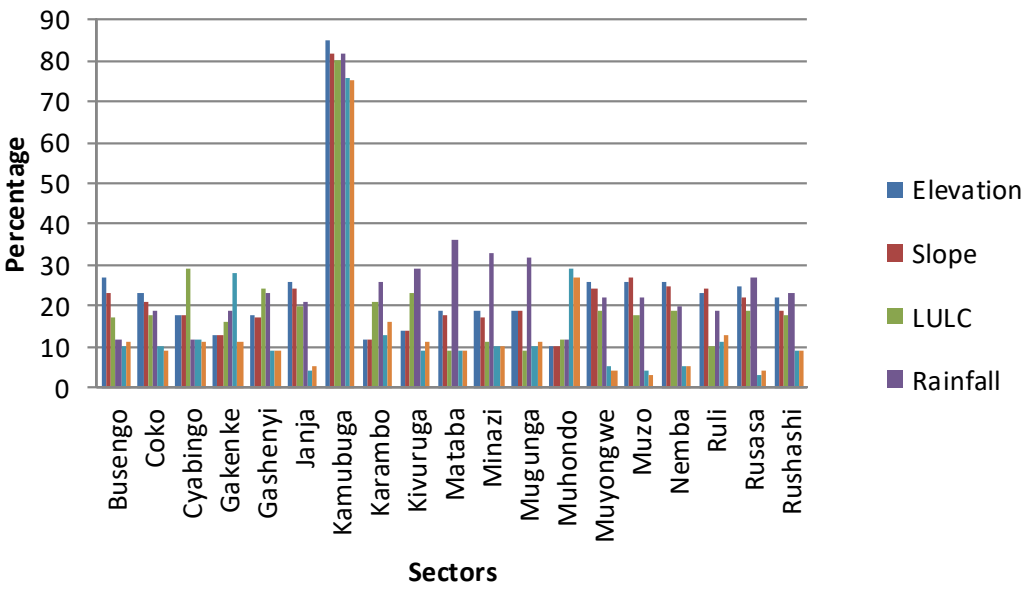

Figure 5. Key landslide causal factors per sector in Gakenke district. 
Table 3. Description of Respondents by age, gender and education.

\begin{tabular}{ccc}
\hline Age & Frequency & Percentage \\
\hline $18-30$ & 36 & $(36)$ \\
$30-42$ & 29 & $(29)$ \\
$42-60$ & 21 & $(21)$ \\
60 above & 14 & $(14)$ \\
Gender & & \\
Female & 42 & $(42)$ \\
Male & 58 & $(58)$ \\
Education & & \\
Illiterate & 13 & $(13)$ \\
Primary & 32 & $(32)$ \\
secondary & 44 & $(44)$ \\
University & 11 & $(11)$ \\
\hline
\end{tabular}

Table 4. Community Awareness on landslide occurrence.

\begin{tabular}{ccccccc}
\hline \multicolumn{5}{c}{ Channels } \\
\hline Information channel & Schools & Meetings & Radio and Television & Trainings & Total \\
\hline Frequency & 14 & 46 & 29 & 11 & 100 \\
Percentage & 14 & 46 & 29 & 11 & 100 \\
& & Causal factors' awareness & & & \\
Awareness & Very high & High & Moderate & Low & None & Total \\
Frequency & 3 & 12 & 22 & 31 & 32 & 100 \\
Percentage & 3 & 12 & 22 & 31 & 32 & 100 \\
\hline
\end{tabular}

Table 5. Impact of landslide on community livelihoods.

\begin{tabular}{ccc}
\hline Livelihood types & Frequency & Percentage \\
\hline Human death and injury & 17 & 17 \\
Displacement & 17 & 17 \\
Lost livestock & 13 & 13 \\
Damage of resources & 25 & 25 \\
Destruction of Hospitals, schools, bridges and houses & 28 & 28 \\
Total & 100 & 100 \\
\hline
\end{tabular}

This was recently reported (Nahayo et al., 2018; Mamon et al., 2017) that lack of formal education and training among people leads to increasing risk due to the reason that basic information, knowledge and skills on drivers to disaster occurrence are not known at local level. This is likely similar to Gakenke district (Table 4) since only meetings and radio and television are the dominant chan- 
nels used to share disaster information with local people without referring to formal education and trainings. In addition, the residents of Gakenke district are likely exposed to landslide because their indigenous knowledge is not valued (Table 6) while planning and executing the risk reduction activities. However, if the local people's knowledge is not recognized, their livelihoods might be affected since these people recognize their area better than anyone. Hence, it would be good to integrate people in planning and executing any activity related to their livelihoods. The results were presented in Table 4 where respondents asserted that landslide related information is, at high extent, communicated to the local community through the local meeting. This was confirmed by $46 \%$ of the population evaluated however, 29 of them mentioned that the information is gained through radio and television, Table 4.

The education and delivery of related education is still at low pace. This is confirmed by low level of awareness among respondents which was ranked at $32 \%$ in Gakenke district. The local people which manifested the awareness on landslide causal factors were $22 \%$, which expressed low level of awareness on landslide which in turn, leads to the increasing hazards exposure since people are not aware of the main causal factors and the adaptation mechanisms.

The residents in Gakenke district are affected by landslide occurrence mainly due to the infrastructure damage such as hospitals, schools, bridges and houses. Apart from infrastructure damage, some resources were affected such as land and water, as confirmed with $25 \%$ informants. However, human death, injuries and displacement were both recorded with $17 \%$ of respondents, respectively. The findings indicated that some measures are implemented toward reducing community susceptibility to landslide in Gakenke district. As shown in Table 6, bench terraces and agroforestry practices are the main measures being implemented to minimize community exposure to landslide, as highlighted by $25 \%$ and $24 \%$, respectively.

The future occurrence likelihood in Gakenke district was estimated by referring to recent events recorded. The results in Figure 6 indicated that Kamubuga as highly susceptible sector (Figure 4) recorded no event in 2019, which expresses low future occurrence likelihood. However, it was noted that Rusasa,

Table 6. Types and effectiveness of initiated exposure reduction measures.

\begin{tabular}{ccc}
\hline Measures & Frequency & Percentage \\
\hline Bench terraces & 25 & 25 \\
Agroforestry & 24 & 24 \\
Rain harvest & 13 & 13 \\
Enforced building code & 13 & 13 \\
Relocating to safe zones & 15 & 15 \\
Valuing indigenous knowledge & 10 & 10 \\
Total & 100 & 100
\end{tabular}




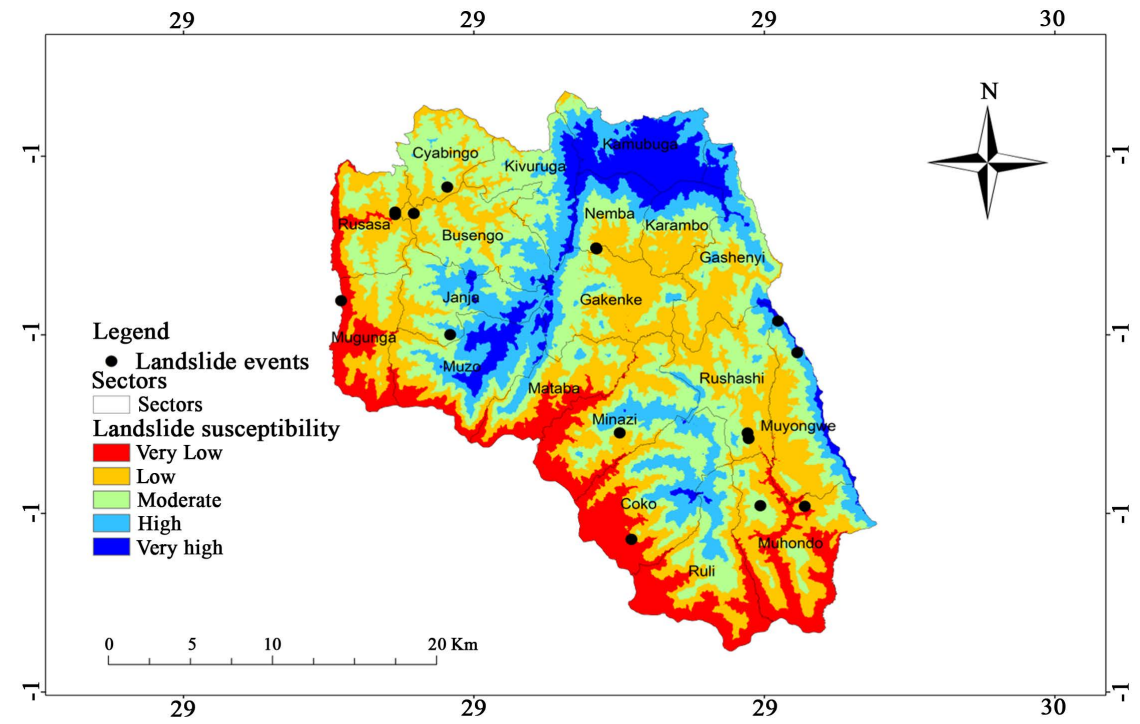

Figure 6. Predicted landslide occurrence.

Muhondo and Cyabingo sectors are likely exposed to future landslide. This is mainly the result of high rainfall across these sectors (Figure 2). Similarly, as recently reported (Ndayisaba et al., 2017), rainfall is among the drivers to landslide in the northwestern Rwanda, and rainfall was ranked among the primal causes of landslide occurrence in Gakenke district (Figure 4 and Figure 5).

However, among the initiated strategy for hazards reduction (Table 6), rain harvest is not highly prioritized compared to agroforestry and bench terraces (Table 6). This calls for strong interventions in mobilizing the local people to harvest the rain in order to minimize the runoff which increases the occurrence likelihood due to elevated land of the study area. This will results from the fact that, as indicated in Figure 6, future landslide occurrence is high in sectors recording high rainfall (Figure $2(\mathrm{c})$ ). Thus, rain harvest would be one of the approaches to reduce future occurrence.

\section{Conclusion}

This study attempted to map landslide susceptibility and assess its impact on community's livelihoods. The authors employed six conditioning factors (elevation, slope, land use, rainfall, soil texture and lithology). The Geographic Information System was used to provide the resulting susceptibility map. It was noted that Kamubuga, Janja, Muzo and Muyongwe sectors are highly susceptible to landslide. The elevation, slope, rainfall and poor land management were ranked as key divers to landslide occurrence in Gakenke district. The results, by using questionnaire among the selected informants indicated that, the local people are still at low level, aware of their exposure to landslide mainly due to channels used to share related information with them. The delivery of education and training is not valued and the rain harvest is still not executed in this area regardless the fact that it is among landslide occurrence conditioning parameters. Based on the findings of this study, it is suggested to ensure delivery of formal 
education and training, rain harvest and valuing local people's indigenous knowledge while planning and executing landslide risk reduction schedule. This study can serve as guiding tool to policy makers and others interested in disaster risk reduction as well. Due to time and budget constraint, it was not easy to consider several factors, which comes to suggesting further research using many factors such as socio-economic, physical and environmental to assess community landslide vulnerability in this area.

\section{Acknowledgements}

The authors greatly express their acknowledgement to the local residents who accepted to invest their time in answering the assigned questionnaire. Their answers made this study complete. The authors also thank all providers of the employed datasets which helped to make the study successful.

\section{Conflicts of Interest}

The authors declare no conflicts of interest regarding the publication of this paper.

\section{References}

Abdulwahid, W. M., \& Pradhan, B. (2017). Landslide Vulnerability and Risk Assessment for Multi-Hazard Scenarios Using Airborne Laser Scanning Data (LiDAR). Landslides, 14, 1057-1076. https://doi.org/10.1007/s10346-016-0744-0

Akgün, A., \& Bulut, F. (2007). GIS-Based Landslide Susceptibility for Arsin-Yomra (Trabzon, North Turkey) Region. Environmental Geology, 51, 1377-1387.

https://doi.org/10.1007/s00254-006-0435-6

Anderson, M. G., \& Holcombe, E. (2013). Community-Based Landslide Risk Reduction: Managing Disasters in Small Steps. Washington DC: The World Bank. https://doi.org/10.1596/978-0-8213-9456-4

Armaş, I. (2011). An Analytic Multicriteria Hierarchical Approach to Assess Landslide Vulnerability. Case Study: Cornu Village, Subcarpathian Prahova Valley/Romania. Zeitschrift für Geomorphologie, 55, 209-229. https://doi.org/10.1127/0372-8854/2011/0055-0040

Ayalew, L., Yamagishi, H., Marui, H., \& Kanno, T. (2005). Landslides in Sado Island of Japan: Part II. GIS-Based Susceptibility Mapping with Comparisons of Results from Two Methods and Verifications. Engineering Geology, 81, 432-445. https://doi.org/10.1016/j.enggeo.2005.08.004

Belle, P., Aunay, B., Bernardie, S., Grandjean, G., Ladouche, B., Mazué, R., \& Join, J.-L. (2014). The Application of an Innovative Inverse Model for Understanding and Predicting Landslide Movements (Salazie Cirque Landslides, Reunion Island). Landslides, 11, 343-355. https://doi.org/10.1007/s10346-013-0393-5

Benineza, G., Rwabudandi, I., \& Nyiransabimana, M. (2019). Landslides Hazards Assessment Using Geographic Information System and Remote Sensing: Gakenke District. IOP Conference Series: Earth and Environmental Science, 389, Article ID: 012015. https://doi.org/10.1088/1755-1315/389/1/012015

Bhatta, G. D., Aggarwal, P. K., Poudel, S., \& Belgrave, D. A. (2016). Climate-Induced Migration in South Asia: Migration Decisions and the Gender Dimensions of Adverse Climatic Events. Journal of Rural and Community Development, 10, 1-23. 
Bizimana, H., \& Sönmez, O. (2015). Landslide Occurrences in the Hilly Areas of Rwanda, Their Causes and Protection Measures. Disaster Science and Engineering, 1, 1-7.

Claeys, C., Arnaud, A., \& Lambert, M.-L. (2017). The Impact of Legal Vulnerability on Environmental Inequalities. A Case Study of Coastal Populations in Guadeloupe (French Antilles). Comptes Rendus Geoscience, 349, 351-358.

https://doi.org/10.1016/j.crte.2017.09.006

Felicísimo, Á. M., Cuartero, A., Remondo, J., \& Quirós, E. (2013). Mapping Landslide Susceptibility with Logistic Regression, Multiple Adaptive Regression Splines, Classification and Regression Trees, and Maximum Entropy Methods: A Comparative Study. Landslides, 10, 175-189. https://doi.org/10.1007/s10346-012-0320-1

Kim, H.-Y., Kim, S.-K., Kang, D.-M., Hwang, Y.-S., \& Oh, J.-E. (2014). The Relationships between Sixteen Perfluorinated Compound Concentrations in Blood Serum and Food, and Other Parameters, in the General Population of South Korea with Proportionate Stratified Sampling Method. Science of the Total Environment, 470, 1390-1400. https://doi.org/10.1016/j.scitotenv.2013.06.039

Mamon, M. A. C., Suba, R. A. V., \& Son, I. L. (2017). Disaster Risk Reduction Knowledge of Grade 11 Students: Impact of Senior High School Disaster Education in the Philippines. International Journal of Health System and Disaster Management, 5, 69.

MIDIMAR (2014). National Contingency for Flood and Landslides (p. 47). Kigali: Ministry of Disaster Management and Refugees (MIDIMAR).

Murillo-García, F. G., Rossi, M., Ardizzone, F., Fiorucci, F., \& Alcántara-Ayala, I. (2017). Hazard and Population Vulnerability Analysis: A Step towards Landslide Risk Assessment. Journal of Mountain Science, 14, 1241-1261.

https://doi.org/10.1007/s11629-016-4179-9

Murillo-García, F., Rossi, M., Fiorucci, F., \& Alcántara-Ayala, I. (2015). Population Landslide Vulnerability Evaluation: The Case of the Indigenous Population of $\mathrm{Pa}$ huatlán-Puebla, Mexico. In Engineering Geology for Society and Territory (Volume 2, pp. 1793-1797). Berlin: Springer. https://doi.org/10.1007/978-3-319-09057-3_317

Nahayo, L., Li, L., Habiyaremye, G., Richard, M., Mukanyandwi, V., Hakorimana, E., \& Mupenzi, C. (2018). Extent of Disaster Courses Delivery for the Risk Reduction in Rwanda. International Journal of Disaster Risk Reduction, 27, 127-132. https://doi.org/10.1016/j.ijdrr.2017.09.046

Ndayisaba, F., Guo, H., Isabwe, A., Bao, A., Nahayo, L., Khan, G., Kayiranga, A., Karamage, F., \& Muhire, E. N. (2017). Inter-Annual Vegetation Changes in Response to Climate Variability in Rwanda. Journal of Environmental Protection, 8, 464. https://doi.org/10.4236/jep.2017.84033

Nsengiyumva, J. B., Luo, G., Nahayo, L., Huang, X., \& Cai, P. (2018). Landslide Susceptibility Assessment Using Spatial Multi-Criteria Evaluation Model in Rwanda. International Journal of Environmental Research and Public Health, 15, 243. https://doi.org/10.3390/ijerph15020243

Piller, A. N. (2016). Precipitation Intensity Required for Landslide Initiation in Rwanda. https://doi.org/10.15760/honors.290

RMA (2018). Rwanda Meteorological Agency, Meteo Rwanda Map Room, Climate Data Library. http://www.meteorwanda.gov.rw/maproom

Rushemuka, P. N., Bock, L., \& Mowo, J. G. (2014). Soil Science and Agricultural Development in Rwanda: State of the Art: A Review. BASE, 18, 142-154.

Shaw, R. (2012). Community Based Disaster Risk Reduction. Bingley: Emerald Group Publishing. https://doi.org/10.1108/S2040-7262(2012)10

USGS (2018). United States Geological Survey, Science for a Changing World. 
https://earthexplorer.usgs.gov

Van Westen, C. J., Rengers, N., Terlien, M., \& Soeters, R. (1997). Prediction of the Occurrence of Slope Instability Phenomenal through GIS-Based Hazard Zonation. Geologische Rundschau, 86, 404-414. https://doi.org/10.1007/s005310050149

Wagesho, N., \& Claire, M. (2016). Analysis of Rainfall Intensity-Duration-Frequency Relationship for Rwanda. Journal of Water Resource and Protection, 8, 706.

https://doi.org/10.4236/jwarp.2016.87058 